\title{
Scientific research in Nepal: Where we are
}

A different attitude in researchers is more essential than a big fund

COMMENTARY Himalayan Journal of Sciences 1(1): 8-9, 2003Download in PDF format

\author{
Bharat B. Shrestha
}

Lack of big funds is not the primary constraint in development of science and technology in Nepal. More important and subtle factors - lack of exchange of information between researchers; lack of co-operation and unhealthy competition between professors and among big institutions (although co-operation is essential for integrated study); data manipulation which prevails from beginners to some established researchers; and professors, the highly expert people in university, being enticed away from their research activity by private teaching institutes.

Role of science and technology (S\&T) in national development is obvious. Recent advances in medical science, computer engineering, genetic engineering, space technology etc are due to enthusiastic research in basic and applied science. However, developing and poor countries are less benefited from these researches than developed countries. Governments of these countries cannot allocate big funds for research in S \& T which is a major constraint in development. Some of the developed countries have their international agencies for bi- and multilateral co-operation and funding in developing countries. Development of S\&T in countries like Nepal largely depends on such funding. The amount of funding may be relatively small but it can bring significant change if properly utilized.

In Nepal research in biological science has 40-50 yrs long history. In early days of this period research was limited to few foreign scientists and occasional visitors. With the establishment of research divisions, councils and introduction of Masters and Ph. D. programs in University, the number of Nepalese researchers also increased. Many Nepalese studied abroad and returned Nepal to work in their fields. Now we have many researchers working in almost all branches of biological sciences. But none of these disciplines have strong foundation, which is unfortunate for the nation. Beside lack of funding there are many technical problems. Some of these problems seem to be simple and very often neglected but important for authenticity of the research output. Knowingly or unknowingly we are committing some mistakes and if not corrected soon we will lag behind many decades in S\&T.

There is a Chinese saying which states "when you exchange apple you will have the same number of apple but when you exchange knowledge you will have double." This is a fact we must learn. This is still more important in research because it is not possible for a scientist to work in all fields. An ecologist may not be able to solve taxonomic problems; for a taxonomist it may be difficult to solve physiological problems. But for understanding, say ecosystem dynamics, information from wide range of fields such as ecology, genetics, microbiology, pathology, physiology, taxonomy, etc are needed which is not possible for a scientist to collect them all. So exchange of information between researchers working in different but related disciplines is indispensable. Lack of this tradition is one important weakness among our researchers. Still more unfortunate in this aspect is the lack of co-operation between researchers working in the same field. We have seen this problem between professors working/teaching subjects, senior and junior researchers, NGOs said to be devoted in same field etc. Just to mention an example, we can take the case of Nepal Flora Project. There is a triangular conflict among Department of Plant Resources (DPR, HMG/N), Royal Nepal Academy of Science and Technology (RONAST) and Central Department of Botany (CDB, TU) to hold leadership. Due to this there has been delay in completion of the project. If we are really dedicated to work leadership should not be the important matter. Conflict like this may have negative feedback effects to donors.

Researchers collect primary data by themselves. For a research there may be various methods of data collection. One may raise questions regarding the reliability of methodology but data collected by following accepted methodology cannot be challenged. We should agree with data if the methodology is correct. Sometimes results may not follow usual/normal patterns. In such case if researcher manipulates actual data to avoid the so called "abnormality" it becomes a serious academic/scientific crime. We are giving wrong information. Somebody else working with such results as a base will also be cheated. In our context data manipulation is another serious problem in research. It prevails from beginners to some established researchers. It is most probable that we are not properly following methodology, have less frequent visit to field in field base works, and/or spend shorter period in field. This makes us less confident to our own result and

http://www.himjsci.com/ - P Powered by Mambo Open Source Generated: 23 January, 2008, 07:24 
we are generally encouraged for data manipulation. So one should have "scientific discipline" to work in this field.

University is not only teaching institution but also research center. To achieve goal teaching should be integrated with research. Beside specific research centers, university teachers are also involved in research. Publication of research work is an important criterion at the time of evaluation for promotion. To accomplish this, many teachers are involved in research in one way or another. The highest honor to university teacher is professorship. Once a teacher is promoted to a professor he/she is expected to have a leading role in research of their specific field. Their able leadership is important for beginners. Unfortunately many of our professors abandon the career as researcher and busy themselves with teaching at higher secondary school level. Some are working as principal in different names such as honorary principal, consultant etc. By this they are making better economic profit but cannot show academic progress, and for the society a research expert in a field is lost.

Needless to say, contemporary scientific world is many years ahead of our national level. We may be benefited from the scientific achievements of other countries in fields such as communication, biotechnology, transportation, computer science etc. But in other discipline such as ecology, medical science, pathology, taxonomy etc. we need research from basic level in our own context. Presently we have ambition to follow the current trend of research in these area but we cannot get significant output from this unless we have strong foundation. For example, although we have a long history of taxonomic study we do not know our actual biological resource. We are rich in such resource but cannot exploit it for national development. Most probably some plants and insects will disappear before we know them. Documentation of every possible details of flora and fauna of Nepal is foremost important pre-requisite for biological research.

Despite these dark faces we have many opportunity and challenges. Nepal is a center of attraction, specially for biological and geological research due to her location, geomorphology, geodynamics, environmental gradient and biodiversity. We should have long-term integrated planning for research on basic, advanced and applied sciences. If we develop the tradition of "scientific discipline" and close co-ordination between individuals and institutions actively involved in research we can bring expected change within time frame. RONAST and Tribhuvan University are expected to take leading role for this goal. It should be taken in serious consideration that we have very limited time to take giant leap in S\&T.

Bharat B. Shrestha is at the Central Dept Botany, Tribhuvan University

E-mail: bhabashre@yahoo.com 